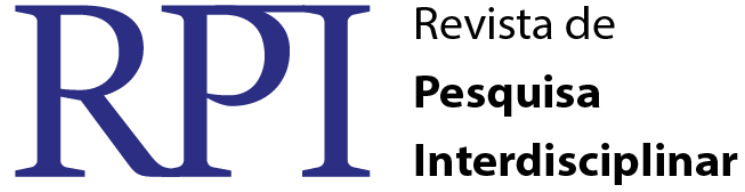

\section{EDUCAÇÃO DE ADULTOS DE ÂMBITO ESCOLAR: ENTRE O QUE É E O QUE DEVERIA SER PARA SE TER EM CONTA O QUE ESTÁ PARA LÁ DOS MUROS DA ESCOLA E SER AGENTE DE MUDANÇA.}

\author{
Armando Loureiro ${ }^{1}$
}

\section{INTRODUÇÃO}

A educação de adultos pode ser um fator de desenvolvimento local, de mudança social, pode contribuir para a integração social dos mais desfavorecidos (CANÁRIO, 1999; LOUREIRO, 2008; MELO, 2008; UNESCO, 2010). No entanto, muitas das suas oferta educativas, sobretudo as de âmbito escolar, ou seja, as referentes à educação compensatória, e também as de âmbito profissional, isto é as que se organizam tendo por pano de fundo o mercado de trabalho, assentam em modelos que se afastam claramente dos adultos que procuram e frequentam tais ações educativas (LOUREIRO, 2012).

Aqui interessa-nos discutir as ofertas educativas de adultos escolares e, na verdade, estas organizam-se, planificam-se e executam-se, muitas vezes, através de metodologias e práticas baseadas em modelos construídos de cima para baixo, uniformes, rígidos, hierarquizados e totalmente afastados da cultura e da vivência dos adultos. Ora, quando assim é e quando um dos principais intervenientes no processo educativo e formativo dos adultos, os educadores, os formadores, os professores, se limitam a reproduzir nos espaços de prática educativa (sala de aula de uma escola, salas de associações, ou outros espaços) os conhecimentos selecionados e organizados a nível central, os processos de educação escolar de adultos arriscam-se a ser fatores de reprodução social, não se tornando verdadeiros mobilizadores de mudança e de igualdade social (LOUREIRO \& CRISTÓVÃO, 2010).

Mas não tem de ser assim, os processos de educação escolar de adultos não têm que ocorrer desta forma, eles podem e devem ter em conta o que está para lá dos muros da escola, o que faz parte da vida quotidiana dos adultos, tal como defendeu e fez Paulo Freire (1975), entre outros (FLECHA, 1997).

\footnotetext{
${ }^{1}$ Universidade de Trás-os-Montes e Alto Douro - Escola de Ciências Humanas e Sociais, Departamento de Educação e Psicologia/Investigador do Centro de Investigação e Intervenção Educativas da Faculdade de Psicologia e de Ciências da Educação da Universidade do Porto (aloureiro@utad.pt) Carine Guedes 
Neste capítulo fazemos essa discussão recorrendo a trabalhos anteriores, reflexões atuais, lançando mão de abordagens sociológicas da educação, do currículo e do conhecimento no campo da educação de adultos, tendo por base uma sociologia da educação de adultos que tem como preocupação perceber e mostrar como o conhecimento instituído neste tipo de currículo tem uma base social, política e económica e que tal facto tem influência nos efeitos sociais que produz e que são, muitas vezes, o de contribuírem para a reprodução social, para a manutenção da ordem social estabelecida, resultando tal facto precisamente do predomínio do tal modelo escolar neste tipo de educação (JARVIS, 1989, 1997; RUBENSON, 1989; FLECHA, 1994a; LLAVADOR \& LLAVADOR, 1996; CABO, 2000). Como refere Cabo (2000:13), o currículo da educação de adultos não é neutro, pois os seus conteúdos, métodos e formas de organização, "são determinados por condicionalismos sociais, económicos, culturais e intelectuais".

\section{Entre o que predominantemente é e o que deveria ser}

Parece ser uma opinião geralmente aceite entre os sociólogos da educação, e não só, que se dedicam à educação de adultos, que esta é dominada pela lógica escolar. A par deste diagnóstico costumam ser defendidas alternativas a esse modelo, que passam, por exemplo, por novas formas de construir os currículos e pela adoção de novas pedagogias (LOUREIRO, 2012).

Correia (1998:143) defende que o campo da educação de adultos é marcado por algumas ambiguidades, que se traduzem numa diferença substancial entre o discurso, que aponta para a centralidade atribuída "ao papel do sujeito na sua própria formação", para a "valorização dos saberes experienciais", para a autonomia do adulto em formação, e a prática racional-tecnicista dominante neste campo. $\mathrm{O}$ autor conclui que a lógica escolar domina a educação de adultos e apresenta-nos o caso concreto do ensino recorrente em contexto prisional.

Segundo Correia (1998:148), o predomínio dessa lógica escolar faz com que esses adultos mantenham uma relação com o saber assente em "modalidades infantis". A possibilidade de mudança, ou seja, o desenvolvimento de um "processo de ruptura com a cristalização das tendências escolarizantes", passa pelo "método autobiográfico" (CORREIA, 1998:150).

De acordo com o autor, esse método leva a uma "ruptura pedagógica", a "uma relativização dos saberes sábios", a "uma reconceptualização do trabalho de formação" (CORREIA, 1998:142). Essa reestruturação passa: por um trabalho de escuta e interpretação conjunta entre educadores e educandos das experiências e saberes passados dos adultos em formação, como forma de se realizar um exercício de "rearticulação e recontextualização que as 
projecte no futuro"; por um trabalho de mediação realizado pelos educadores, que pode assumir diversas modalidades, e cujo objectivo é a exteriorização dos saberes desses adultos; enfim, por um trabalho cujo centro passa a ser o adulto e o seu processo de aprendizagem e autoformação mediada (CORREIA, 1998:151).

Josso $(2002,2004)$ é uma das principais representantes desta linha de investigação e, tal como o autor anterior, afirma que a base deste tipo de relação pedagógica é a realização de uma retrospectiva do passado dos adultos e dos seus saberes, procurando-se capitalizar para o futuro parte desses mesmos saberes. Afirma ainda que as histórias de vida mostram "que todos nós temos competências genéricas, transversais", como a capacidade de comunicação, a criatividade e a habilidade (JOSSO, 2004:23).

São estas e outras competências e saberes que devem ser o início do processo organizativo das ofertas educativas de adultos. A educação de adultos em geral e a que visa proporcionar aprendizagens de cariz escolar deveria estar aberta a implementar este tipo de metodologia e, desta forma, aproximar-se da realidade vivida pelos educandos.

Canário (1999) critica igualmente o predomínio da forma escolar na educação de adultos. Segundo o autor, a educação de adultos mantém-se "refém da forma escolar" (CANÁRIO, 1999:107), que não considera a "singularidade", "a contextualização" e a "dependência do público", tal como não valoriza os saberes adquiridos pelos adultos noutros contextos, nem as suas experiências, contribuindo, desta forma, para o desenvolvimento de uma relação de exterioridade dos atores/adultos com o conhecimento que lhes é transmitido, pois o modelo escolar caracteriza-se por uma "lógica de ruptura com a experiência” (CANÁRIO, 1999:100,109). Lógica essa que está na base de outra das suas características: a conceção e organização tecnicista da educação de adultos, que assenta no levantamento de necessidades dos adultos, mas que deixa completamente de lado o levantamento das potencialidades desses adultos, daquilo que são os seus recursos, os seus saberes. Não se trata, portanto, apenas de olhar para os adultos como atores com necessidades, mas também de os ver como alguém que em si mesmo são um recurso que deve ser tido em conta no ato educativo.

No mesmo sentido, de um predomínio do modelo escolar, vão as apreciações de Lima (1996:61) relativamente ao retrato da situação vivida em Portugal em meados dos anos 90: "a reforma educativa desinstitucionalizou e fragmentou o sector da Educação de Adultos, retirandolhe unidade e subjugando-o ao modelo escolar". Conclusões similares tiram Silva e Rothes (1998). Apreciações semelhantes em relação à realidade espanhola são realizadas por diversos autores (LLAVADOR, 1993; FLECHA, 1997b; CABO, 2000). A situação atual em Portugal 
mantém, no geral, esta forte tendência e mais grave ainda é a presente desvalorização política do setor da educação de adultos.

Também Freire (1975) fez uma forte crítica ao modelo escolar na educação de adultos (educação bancária), defendendo em alternativa uma educação problematizadora. A educação bancária, cujo protótipo é a educação escolar, assenta no depositar, narrar, transferir e transmitir conhecimentos dos educadores, que são os que sabem, para os educandos, que nada sabem e assim se vêem transformados em meros recipientes prontos a arquivar o conhecimento que lhes é transmitido. Esta conceção "nega a educação e o conhecimento como processos de busca" (FREIRE, 1975: 83). A educação problematizadora, pelo contrário, assenta no "saber com os educandos" (FREIRE, 1975: 88), na superação da contradição educador-educando, na ideia de que ambos têm saber e de que ambos se educam, num processo de construção coletivo de consciencialização que leva à mudança social.

Jarvis (1989) identifica dois tipos de currículo na educação de adultos. O currículo clássico e o currículo romântico. O primeiro baseia-se na educação vinda de cima, isto é, num tipo de educação na qual os educandos não têm interferência na seleção e forma de organização do conhecimento, bem como na forma como ele é transmitido. Exemplo deste tipo de educação no campo da educação de adultos é a educação vocacional e a educação liberal. No seu conjunto, todas as formas de educação vindas de cima são o espelho de tipos de seleção hegemónicos e uniformes dos conhecimentos, que traduzem o domínio das elites. O segundo tipo de currículo baseia-se na educação de iguais, e nestes casos são os educandos que seleccionam os conteúdos.

O tipo de currículo que predomina na educação de adultos é o primeiro, que corresponde ao tal modelo escolar e este tipo de currículo, para além do efeito reprodutor que tem (JARVIS, 1989, 1997), entra em contradição com alguns dos princípios da educação de adultos. Por exemplo, ele não reconhece os saberes extra-escolares, mas os adultos têm muitos outros tipos de saberes que adquirem noutros contextos (JARVIS, 1989) e a educação escolar de adultos ou a que visa que os adultos realizem aprendizagens de âmbito escolar deveria considerar o que está para lá dos seus muros para, desta forma, ter maiores possibilidades de ser um agente de mudança e de promoção de igualdade social.

Flecha $(1990,1994 a, 1994 b)$ é outro dos autores que critica o predomínio do modelo escolar e os seus efeitos em termos curriculares de adultos. Para Flecha (1990:81), os currículos em educação de adultos devem basear-se na "inteligência cristalizada" dos adultos que assenta no seu saber experiencial. Portanto, o currículo e os seus conteúdos devem ser feitos em articulação com essa experiência, o mesmo se passando com o tipo de pedagogia a implementar. Defende ainda, o autor, que na construção desses currículos deve ser tida em conta a diversidade de alunos, RPIRevista de Pesquisa Interdisciplinar, Cajazeiras, v. 1, Ed. Especial, 52 - 63, set/dez. de 2016. 
a não sequencialidade uniforme dos conteúdos, e a implementação de instrumentos para preparar os adultos a aprender a aprender (Flecha, 1990).

Llavador e Llavador (1996:15), referindo-se à institucionalização da educação de adultos, afirmam que tal institucionalização tem violentado as práticas (o currículo e a acção docente) deste tipo de educação, "ao obrigá-las a submeter-se a formatos pré-estabelecidos que limitam, quando não excluem de forma definitiva, a possibilidade da emergência de outros modos de entender a tarefa educativa de e com a população adulta", sendo o "traço institucional que melhor caracteriza essas políticas mais ou menos recentes o escolarismo, que (...) materializa o controle técnico e conduz à despolitização do sector". Críticas semelhantes em relação à educação em geral e à sua despolitização podem ser vistas em Halliday (1995) e, no que toca à educação de adultos, em Lima (2000).

$\mathrm{Na}$ perspectiva daqueles dois autores (e com base numa análise histórica do que tem ocorrido no seu país - Espanha), a educação de adultos tem sido dominada pelo escolarismo e pela burocratização. Este facto tem-se traduzido, entre outros aspetos: numa concentração do controlo sobre a forma e conteúdo dos conhecimentos selecionados e transmitidos; numa uniformização dos modelos formais adotados; numa sobrevalorização do conhecimento escolar e consequente desvalorização de outros tipos de conhecimento; numa organização do conhecimento baseado numa lógica disciplinar e por módulos; numa organização do tempo semelhante à da escola; na transmissão do mesmo conhecimento para todos; numa submissão da prática, entendase exercício profissional docente e sua relação pedagógica com os educandos, à produção teórica existente, o que faz com que os segundos deixem à porta os seus saberes e os primeiros vejam a sua atividade muitas vezes reduzida a um mero exercício de aplicação dos conhecimentos produzidos externamente (LLAVADOR \& LLAVADOR, 1996).

Relativamente a este último aspeto não podemos deixar de referir que embora seja verdade que a ação dos docentes e formadores de adultos esteja, muitas vezes, fortemente estruturada, balizada, sobretudo aquela que se exerce em espaço escolar, há sempre a possibilidade de se procurarem e encontrarem, como diria Giddens (2000) a propósito da ação humana em geral, espaços de autonomia que permitem dar "voz" aos adultos e exercer a função docente de forma diferente, de uma forma que não se limite à reprodução de um conhecimento construído e organizado centralmente e que, pelo contrário, recontextualize esse conhecimento e gere possibilidades de se criarem durante o próprio processo educativo com os adultos momentos de construção de um novo conhecimento.

Ainda de acordo com aqueles autores, o currículo da educação de adultos não deve assentar em tais pressupostos, ou seja, no escolarismo e na burocratização. Ele deve ser RPIRevista de Pesquisa Interdisciplinar, Cajazeiras, v. 1, Ed. Especial, 52 - 63, set/dez. de 2016. 
organizado de forma a poder ser revisto e adaptado às mudanças sociais ocorridas. Deve partir da realidade, do quotidiano vivido pelos adultos, das suas experiências. Por isso, deve ser aberto e diversificado e basear-se na ideia de Vygotski de "zonas de desenvolvimento próximo" (LLAVADOR e LLAVADOR, 1996:64).

Por isso também, a sua elaboração deve partir de "objectivos e conteúdos que tenham em conta o contexto específico da produção e utilização do conhecimento pela pessoa adulta", o que exige não partir dos conhecimentos académicos, mas sim dum trabalho de explicitação e formulação rigorosa dos "problemas enfrentados pelos adultos para que possam" ser, posteriormente, "tratados adequadamente" do ponto de vista "académico" (LLAVADOR e LLAVADOR, 1996: 91). Ou seja, o processo educativo deve ser inverso ao do modelo escolar, deve ir do particular para o geral. Este ponto de vista faz os autores defenderem que se dê "voz" a quem na prática, os educadores e educandos, faz uso do conhecimento. Ou seja, na sua perspetiva o conhecimento sobre educação de adultos deve partir da prática, o que pressupõe a participação na produção desse conhecimento daqueles dois tipos de atores, o que faz com que se encarem esses adultos não já como meros processadores de conhecimento, mas como produtores, criadores do conhecimento que usam. Tal exige um trabalho conjunto de educadores e educandos no sentido de desconstruirem a sua prática, o que passa por uma análise "que integre simultaneamente a teoria-prática-investigação”, isto é, formalização dessa prática. Essa é a única forma de mudar significativamente a relação pedagógica existente, bem "como os conteúdos do currículo" (LLAVADOR e LLAVADOR, 1996:119,124).

Mas esse trabalho de construção do conhecimento da educação de adultos, que se materializa também nos currículos, não acaba neste dois tipos de interlocutores, como terá fícado percebido pela forma como começamos o parágrafo anterior. Trata-se de um processo muito mais amplo, designado de "aprendizagem humana culturalmente mediada", para o qual são convocadas a "comunidade social" e suas práticas e a objetivação do conhecimento resultante das mesmas, sendo este trabalho efetuado por "professores, alunos, investigadores ou teóricos" (LLAVADOR e LLAVADOR, 1996: 125).

Cabo (2000) é outro dos autores que se tem dedicado às questões curriculares na educação de adultos e que nos apresenta uma análise semelhante às descritas acima. Também ele conclui que o modelo escolar domina este tipo de educação, pois "os centros ou lugares onde se desenrolam as atividades de educação de adultos copiam ou imitam a educação formal" em diversos aspetos. Por exemplo, nos centros de educação de adultos "de muitas cidades de Espanha realizam-se provas de certificação" escolar "todas as semanas". Mas a imitação mais grave, segundo o autor, é o próprio tipo de "conhecimento" que nesses locais é transmitido (CABO, RPIRevista de Pesquisa Interdisciplinar, Cajazeiras, v. 1, Ed. Especial, 52 - 63, set/dez. de 2016. 
2000: 20,66). É contra a "visão instrumentalista", "técnico-burocrática" da educação de adultos, que se traduz, entre outros aspetos, na construção prescritiva do currículo a partir dum "conhecimento académico" descontextualizado, que o autor se bate (CABO, 2000:10,38). Em Portugal facilmente podemos encontrar situações semelhantes às descritas por Cabo (2000). Mesmo em processos educativos de adultos que supostamente se baseiam no modelo da educação não-formal vemos, muitas vezes, a replicação do modelo formal da educação escolar. Nestes casos há uma forte responsabilidade dos educadores, dos formadores de adultos e de quem os supervisiona. Uma explicação possível para que tal aconteça será, na nossa perpetiva, a falta de formação académica e contínua específica em educação de adultos de muitos dos que trabalham neste campo.

Cabo (2000), tal como os anteriores autores, defende que a estrutura da construção curricular (os seus conteúdos, a sua organização) deve assentar nas vivências, nas experiências, nas atividades das pessoas. Experiências essas que são a base dos "conhecimentos não formais" dos adultos (CABO, 2000: 69). É este tipo de conhecimento que, de acordo com o autor, deve ser incluído no currículo.

O conhecimento não formal é aquele tipo de conhecimento que resulta da articulação entre pensamento e atividade humana, ou seja, aquele que procede do pensamento que agrupa, ordena e sistematiza a experiência quotidiana. São aqueles conhecimentos que estão relacionados com as atitudes, as habilidades, os procedimentos, os mecanismos e todo o conjunto de conhecimentos "que utilizamos como guia efectivo das acções" (CABO, 2000:159). É na interacção social, na comunicação, que se "aprende a perceber, a sentir e a pensar", é aí, enfim, que se adquire o “conhecimento não formal", assim, o fundamento deste conhecimento está "na praxis: o acto, a acção, o discurso, a interacção" (CABO, 2000:112,152). Concebido desta forma, este tipo de conhecimento tem uma dupla vertente, é conteúdo e é, simultaneamente, comunicação, ou interacção.

Cabo (2000:154) defende ainda, para além da inclusão deste tipo de conhecimento no currículo, a aprendizagem do seu uso por parte dos adultos, pois "o uso do conhecimento não formal, quer dizer aquilo que cada um conhece, o seu saber, possibilita o seu uso discricional" e é na medida em que cada um aprende a utilizar esse conhecimento discricionalmente, "mediante a sua consciência reflexiva", que se torna membro ativo da sociedade e é capaz de expressar os seus próprios interesses. Esta visão está muito próxima da que Freire (1975) defendeu.

Portanto, segundo Cabo (2000), o currículo e o discurso da educação de adultos devem basear-se no conhecimento não formal dos adultos e na aprendizagem do seu uso por parte deles. Isso implica a formalização desses conhecimentos não formais no próprio currículo, na qual RPIRevista de Pesquisa Interdisciplinar, Cajazeiras, v. 1, Ed. Especial, 52 - 63, set/dez. de 2016. 
devem participar todos os agentes educativos. O que passa pela "construção social do currículo", que deve ser concebida de forma a encarar "os educadores e educandos (...) como agentes educativos" capazes de realizarem uma reflexão "conjunta" acerca "das experiências sociais e pessoais da realidade que os envolve". O diálogo, a discussão e o debate realizado a partir dessas experiências e saberes associados permite a construção e reconstrução do conhecimento, possibilitado precisamente por esse processo que leva os atores à tomada de consciência reflexiva sobre aquilo que os rodeia e, dessa forma, se torna possível realizar o tal uso do conhecimento não formal (CABO, 2000:70,71).

Também Canário (1999) defende que a educação de adultos deve estruturar-se em princípios completamente contrários aos que a dominam. Ela deve, entre outros aspetos: assentar numa lógica de pesquisa por parte dos adultos, de resolução de problemas; no princípio da valorização e reconhecimento dos múltiplos saberes adquiridos pelos adultos, nomeadamente os vindos da experiência, o que permite encarar o adulto como o principal recurso da sua educação e encará-lo como um sujeito capaz de transformar as suas experiências em "saberes susceptíveis de serem transferidos para outras situações" (CANÁRIO, 1999:112); enfim, numa lógica que promova a reflexão na ação e sobre a experiência como forma de construção de conhecimento, numa lógica de revalorização epistemológica da prática, assente na sua interação com a teoria (CANÁRIO, 1999, 2000b).

O que predominantemente tem sido nos processos educativos de adultos não tem contribuído, na maior parte dos casos, para uma melhoria das condições de vida dos adultos que procuram e frequentam as ofertas educativas existentes.

Dubar e Gadéa (2001:151,155), referindo-se ao caso francês e aos efeitos da formação contínua em termos de mobilidade social, confirmam a tendência reprodutora da educação de adultos: "Como na escola, a formação contínua veicula desigualdades sociais e relações de dominação que reproduzem o capital cultural herdado e transformam-no em méritos individuais justificando a hierarquia das posições sociais e profissionais (...). A esperança de uma compensação das desigualdades escolares nunca se realizou verdadeiramente no contexto da formação pós-escolar francesa".Ao mesmo tipo de conclusões poderemos chegar quando nos referimos à chamada educação compensatória de adultos, ou seja, quando nos referimos às ofertas escolares de segunda oportunidade dirigidas a adultos. Também aqui os efeitos têm sido reduzidos.

\section{É possível ter em conta o que está para lá dos muros escolares}

RPIRevista de Pesquisa Interdisciplinar, Cajazeiras, v. 1, Ed. Especial, 52 - 63, set/dez. de 2016. 
Apesar do predomínio do modelo escolar na educação de adultos existem vários exemplos de formas de organização e implementação de processos educativos neste campo que nos mostram que é possível ter-se em conta o que está para lá dos muros escolares, mesmo quando o objetivo final dos processos educativos é proporcionar aos adultos aprendizagens de âmbito escolar.

Podemos enunciar os trabalhos de alfabetização e neoleitura, cujo formato é o de uma tertúlia literária, de Flecha (1997,a,b), que se têm baseado no método dialógico, cujo percursor foi Freire (1975). Como refere o autor, tem-se tratado de um processo de transformação cujo ponto de partida é o quotidiano laboral, social, familiar e afetivo desses adultos (Flecha, 1997a). A pedagogia dialógica assenta em vários princípios, dos quais destacamos: o diálogo igualitário, a inteligência cultural, a dimensão instrumental e a transformação.

O primeiro princípio assenta na horizontalidade de relacionamento entre educadores e educandos. Nele está pressuposto que ninguém impõe nada a ninguém, que todos têm saberes, e que todos aprendem uns com os outros. O educador assume um papel de coordenação e aprende tanto ou mais que os adultos em alfabetização, que por seu turno também aprendem uns com os outros através dos diálogos, isso faz com que estes "deixem de ser receptores passivos de conhecimentos e passem a ter uma postura activa gerando-os" (FLECHA, 1997a:18).

Este princípio está intimamente relacionado com o da inteligência cultural, que consiste em considerar que todos os adultos têm capacidades múltiplas, conhecimentos múltiplos resultantes da pluralidade das suas experiências, e é a partir do diálogo igualitário que essa inteligência vai sendo despertada e transferida para o novo contexto, o da tertúlia. Esse processo fundamenta-se em três passos: "autoconfiança interactiva", ou seja, no reconhecimento por parte do grupo que todos têm capacidades provenientes dos seus contextos vivenciais (saber calcular, etc.); "transferência cultural”, isto é, no descobrimento de que a inteligência cultural que possuem pode ser transferida e aproveitada noutro contexto, o da alfabetização e neoleitura; e a "criatividade dialógica", que consiste na valorização das múltiplas interpretações realizadas pelos adultos das obras literárias que são usadas para realizarem o seu processo educativo (FLECHA, 1997a: 25,26).

Neste tipo de educação de adultos, assente na perspetiva dialógica, não há programas, nem currículos, nem uma programação rígida do tempo, mas tal não impede que se realize uma aprendizagem instrumental. Pelo contrário, esta perspetiva conjuga a dimensão relacional com a instrumental e assim realiza-se a "aprendizagem instrumental daqueles conhecimentos e habilidades que se considera necessário possuir" por parte do grupo. Desta forma participada se foi aprendendo a ler, a escrever, a interpretar obras literárias, etc., o que leva o autor a considerar RPIRevista de Pesquisa Interdisciplinar, Cajazeiras, v. 1, Ed. Especial, 52 - 63, set/dez. de 2016. 
que a partir desta metodologia têm sido aprendidos "mais conteúdos tradicionais que nas aulas tradicionais" (FLECHA, 1997a: 33,34).

Esta educação de adultos, assente no processo dialógico, acredita na transformação, na emancipação dos adultos, no papel modificador da educação (FLECHA, 1997a). Acredita, como diria Freire (1997) na esperança da transformação baseada numa "Pedagogia da Esperança". Para Flecha (1997b:180) a educação de adultos, nomeadamente a "educação básica de adultos", deve basear-se no processo dialógico e seus princípios, se quer ter sucesso.

Há também casos de construção curricular que se afastam do modelo escolar, ao assentarem grande parte da sua filosofia na metodologia do balanço de competências, (PIRES, 2005). Em Portugal, o caso dos cursos de Educação e Formação de Adultos (EFA) é, ou melhor foi, dos mais visíveis nesta matéria e será aquele que maior possibilidade apresenta de realizar tal afastamento. Dizemos foi porque embora ainda existam a sua oferta foi drasticamente diminuída nos últimos anos.

Nessa forma de construção curricular está presente, pelo menos do ponto de vista teórico, a influência de Freire (1975) e das suas ideias fundamentais. Os temas de vida, as questões geradoras, existentes em tais cursos, são termos que nos mostram a presença do autor. Defendemos que as abordagens sociológicas da educação devem continuar a dedicar-se ao estudo dos currículos da educação de adultos em geral e devem dar particular atenção às novas formas de construção curricular.

O modelo de Bernstein (1993) relativo à classificação e ao enquadramento do conhecimento escolar seria, em nossa opinião, muito útil para se analisar e ter uma melhor compreensão dos currículos na área da educação e formação de adultos. De grande utilidade é também a análise feita por Perrenoud (1995) relativamente ao currículo formal e currículo real, quando se debruça sobre a ação dos professores em sala de aula. Tendo ainda em consideração os trabalhos de Bernstein $(1993,1998)$ pensamos que a sua teoria do discurso pedagógico oficial, com os seus campos de produção, recontextualização de reprodução desse discurso, é muito pertinente para uma análise do que se passa a este respeito na educação de adultos. É verdade, como já referimos noutro local, "que já foram feitos alguns estudos usando a sua teoria no campo da educação de adultos, procurando ver como em contexto de trabalho os agentes educativos fazem uso desse discurso pedagógico oficial (Loureiro, 2009a; Loureiro \& Cristóvão 2010), mas muito está ainda por fazer" (LOUREIRO, 2012: 129).

No caso concreto das novas formas de construção curricular na área da educação de adultos e, particularmente, na que se refere à que consubstancia os cursos EFA, seria pertinente 
analisar os aspetos mais inovadores desse processo e tentar perceber quais os seus efeitos. Que diferenças existem relativamente aos currículos tipicamente escolares? Essas diferenças têm implicações na forma de trabalhar dos atores envolvidos nesses processos educativos? Existirem temas de vida que devem ser trabalhados transversalmente nas diferentes áreas de competência a atingir pelos adultos em formação faz com que os formadores realizem um trabalho mais colaborativo? Faz com que exista maior entreajuda entre os elementos das equipas técnicas?

A existência de tais temas de vida permite pôr em prática a questão da “interdisciplinaridade"? Este processo de construção curricular permite dar "voz" (ARONOWITZ \& GIROUX, 1993) aos adultos? Permite ter em conta no processo educativo o que está fora dos muros da escola e que faz parte das vidas dos adultos?

Não se pretende dar resposta definitiva a estas questões, faz-se apenas e quando muito, uma aproximação às mesmas, a partir de uma breve apresentação e reflexão sobre esta modalidade curricular, procurando destacar os aspetos que consideramos serem mais inovadores e que, à partida, permitiriam responder afirmativamente às últimas questões colocadas.

Os cursos EFA são destinados a pessoas com idade igual ou superior a 18 anos, com qualificação considerada inadequada para ingressar e/ou progredir no mundo do trabalho "e, prioritariamente, sem a conclusão do ensino básico ou do ensino secundário" (Artigo $\mathrm{n}^{\mathrm{o}} 2$ da Portaria $n^{\circ}$ 230/2008, de 7 de Março) e foram criados em 2000 pela Agência Nacional de Educação e Formação de Adultos. Na maior parte dos casos estes cursos assentam numa lógica de dupla certificação: escolar e formação profissionalizante, nos diversos graus de ensino e níveis de formação profissional.

Estes cursos, como nos dizem vários autores, constituíram-se como um novo modelo de educação e formação de adultos em Portugal (ÁVILA, 2008; CAVACO, 2008; LOUREIRO, 2009a,b). Em termos de organização curricular podemos distinguir, como elementos inovadores, cinco aspetos.

Como refere Rothes (2009), embora a formação de base e a formação profissionalizante se baseiem em conceções curriculares diferentes, a primeira na lógica das competências e a segunda na lógica das unidades capitalizáveis do Instituto de Emprego e Formação Profissional, pretendese que exista uma efetiva articulação entre as duas, evitando, desta forma, a separação tradicional que tem ocorrido entre educação escolar e formação profissional.

O segundo aspeto a salientar está no facto de a construção curricular, que diz respeito à formação escolar, se basear, não no modelo disciplinar tradicionalmente escolar, mas num referencial de competências-chave estruturadas em diferentes áreas de competência a atingir ou a RPIRevista de Pesquisa Interdisciplinar, Cajazeiras, v. 1, Ed. Especial, 52 - 63, set/dez. de 2016. 
desenvolver, que são transversalmente organizadas e articuladas por temas de vida relevantes para os adultos em formação (ÁVILA, 2008).

Uma das inovações mais relevantes destes cursos está expressa na Portaria n. ${ }^{\circ}$ 230/2008, de 7 de Março, que nos permite verificar que a sua organização curricular é flexível ao ponto de possibilitar que os adultos, após um processo prévio de reconhecimento, validação e certificação de competências - assente na metodologia de balanço de competências - possam seguir itinerários diferenciados nos cursos de acordo com as competências que lhe foram reconhecidas, embora existam sempre horas mínimas de formação a cumprir. A responsabilização das equipas pedagógicas pela construção do plano curricular de cada curso pelo qual é responsável é outro dos pontos inovadores destes cursos. Como refere Rothes (2009, p.307) cada equipa deve construir o plano curricular "em torno das duas componentes e das diferentes áreas de competências-chave com o suporte de temáticas transversais - os Temas de Vida (TV) -, que assegurem a coerência e a relevância do projecto formativo".

Por fim, destacamos ainda a possibilidade de se fazer uma gestão local do currículo. Ou seja, se a instituição formadora de um curso achar ser pertinente para o grupo de formandos pode substituir, após a devida autorização superior, "uma das unidades em que se encontra estruturado o curso por outra equivalente que se revele mais adequada ao contexto ou à natureza da área profissional" (Portaria n. ${ }^{\circ} 230 / 2008$, de 7 de Março).

Este e outros modelos similares de construção curricular aproximam-se daquilo que vários autores, tais como os referidos na secção anterior, defendem deverem ser os currículos na educação de adultos. Também nós pensamos dessa forma e acreditamos que estes modelos e outros ainda menos formalizados que têm em consideração a vida, a realidade dos adultos em formação, podem, mais facilmente, contribuir para uma das principais finalidades da educação de adultos: ser um meio de transformação social, de igualdade e de inclusão social, ser um potencial veículo de ascensão social dos adultos que procuram e frequentam as diferentes ofertas educativas neste campo.

\section{Uma nota final}

Mas o que acabamos de escrever no parágrafo anterior não quer dizer que tenhamos a ilusão que o simples facto de tais modelos existirem faça com que se concretizem automaticamente tais objetivos da educação de adultos. Desde logo porque eles dependerão sempre de quem os põe em prática, de quem está no campo da prática educativa e pode ocorrer, e 
ocorre, que quem aí desenvolve a sua atividade seja um mero reprodutor de conteúdos e modalidades de trabalhar que mais não são que uma réplica da modalidade escolar, mesmo que o contexto onde desenvolve a sua prática profissional lhe permita ser, juntamente com os adultos em processo educativo, recontextualizador e produtor de conhecimento, ser agente de conscientização, ser agente de mudança. Portanto, não basta existirem modelos e processo educativos de adultos menos formais, mais afastados do modelo escolar, é preciso que quem está na prática se afaste dessa forma de pensar e exercer o processo educativo com adultos, é preciso que acredite que é possível educar de outra forma quando se trabalha com adultos, é preciso que se reeduque no sentido de aprender a ser educador, formador, professor de outra forma, de uma forma que parta do que é a realidade dos adultos, do que são os seus saberes, a sua linguagem, a sua cultura e os seus interesses. Foi essa a maneira de trabalhar de Freire $(1975,1977)$ e de outros, não muitos mais.

É verdade que difícil trabalhar, educar dessa forma, é mais fácil reproduzir compêndios, instrumentos que sustentam rotinas e modalidades de avaliação uniformes, mas, dessa forma, estáse verdadeiramente a educar adultos? E qual é o efeito desse tipo de educação na vida pessoal e social desses adultos?

\section{BIBLIOGRAFIA}

ARONOWITZ, S. \& GIROUX, H. Posmodern education. Politics, culture, \& social criticism. Minneapolis: University of Minnesota, 1993.

ÁVILA, P. A literacia dos adultos. Competências-chave na sociedade do conhecimento. Lisboa: Celta, 2008.

BERNSTEIN, B. La estructura del discurso pedagógico. Vol. IV. Madrid: Morata, 1993.

BERNSTEIN B. Pedagogía, control simbólico e identidad-Teoría, investigación y crítica.Vol. V. Madrid: Morata, 1998.

CABO, A. Hacia una sociología curricular en educación de personas adultas. Barcelona: Octaedro, 2000.

CANÁRIO, R. Educação de adultos. Um campo e uma problemática. Lisboa: Educa, 1999.

CANÁRIO, R. Formação profissional: problemas e perspectivas de futuro. Forum, n. 27, p.125-139, 2000.

CAVACO, C. Adultos pouco escolarizados. Diversidade e interdependencia de lógicas de formação. Tese de Doutoramento. Universidade de Lisboa, Lisboa, 2008.

RPIRevista de Pesquisa Interdisciplinar, Cajazeiras, v. 1, Ed. Especial, 52 - 63, set/dez. de 2016. 
DUBAR, C. \& GADÉA, C. Sociologia da formação pós-escolar. IN: CARRÉ, P. \& CASPAR, P. (Dir.).Tratado das ciências e das técnicas da formação. Lisboa: Instituto Piaget, p.143-160, 2001.

FLECHA, R. Educación de las personas adultas. Propuestas para los años noventa. Barcelona: El Roure, 1990.

FLECHA, R. Educación de personas adultas: tarea pendiente de la modernidad. IN:

GIROUX, H. \& FLECHA, R. Igualdad educativa y diferencia cultural. Barcelona: Roure, p.27-56, 1994a.

FLECHA, R. Habelencias básicas da poboación adulta. IN: OSÓRIO, A. et al. (eds.),

Educación de adultos nunha sociedade en transformación. Santiago de Compostela: DXPL, p.55-71, $1994 b$.

FLECHA, R. Compartiendo Palabras. Barcelona, Paidós, 1997a.

FLECHA, R. Compensación, aceleración, inteligencia cultural. IN: CARRASCO, J. (coord.), Educación de adultos. Barcelona: Ariel, p.177-187, 1997b.

FREIRE, P. A pedagogia do oprimido. Porto: Afrontamento, 1975.

FREIRE, P. Pedagogia da Esperança. Um Reencontro com a Pedagogia do Oprimido. São Paulo: Paz e Terra, 1997.

GIDDENS, A. (2000). A Dualidade da Estrutura. Oeiras: Celta.

HAllIDAY, J. Educación, gerencialismo y mercado. Madrid: Morata, 1995.

JARVIS, P. Sociología de la educación continua y de adultos. Barcelona: El Roure, 1989

JARVIS, P. Sociology of adult education. IN: SAHA, L. (Ed.), International encyclopedia of the sociology of education. Oxford: Pergamon, p.168-172, 1997.

JOSSO, C. Experiências de vida e formação. Lisboa: Educa, 2002. 